\title{
The Binding of Human IgG to Minipig FcyRs - Implications for Preclinical Assessment of Therapeutic Antibodies
}

\author{
Jerome Egli ${ }^{\prime}$ - Tilman Schlothauer ${ }^{2}$ - Christian Spick ${ }^{2}$ - Stefan Seeber ${ }^{2}$ - Thomas Singer ${ }^{\prime}$. \\ Alex Odermatt ${ }^{3} \cdot$ Antonio Iglesias $^{\prime}$ (i)
}

Received: 5 November 2018 / Accepted: 16 January 2019 / Published online: 5 February 2019

(C) The Author(s) 2019

\begin{abstract}
Purpose The Göttingen minipig is a relevant non-rodent species for regulatory toxicological studies. Yet, its use with therapeutic antibodies has been limited by the unknown binding properties of human immunoglobulins (huIgG) to porcine Fc gamma receptors $(\mathrm{poF} \gamma \mathrm{R})$ influencing safety and efficacy readouts. Therefore, knowing IgG-Fc $\gamma \mathrm{R}$ interactions in the animal model is a prerequisite for the use of minipigs in preclinical safety and efficacy studies with therapeutic antibodies. Methods Here, we describe the cloning and expression of poFc $\gamma$ Rs and their interactions with free and complexed human therapeutic IgG1 by surface plasmon resonance and flow cytometry.

Results We show here that poFc $\gamma \mathrm{RIa}$, poFc $\gamma \mathrm{RIIa}$, and poFc $\gamma$ RIIb bind huIgG1 antibodies with comparable affinities as corresponding huFc $\gamma$ Rs. Importantly, poFc $\gamma$ Rs bind huIgG immune complexes with high avidity, thus probably allowing human-like effector functions. However, poFcyRIIIa binds poIgGla but not to huIgGl.

Conclusions The lack of binding of poFcyRIIIa to huIgG1 might cause underestimation of FcyRIIIa-mediated efficacy or toxicity as mediated by porcine natural killer cells. Therefore, the suitability of minipigs in preclinical studies with human therapeutic antibodies has to be assessed case by case.
\end{abstract}

Electronic supplementary material The online version of this article (https://doi.org/l 0. I007/s I 1095-0 19-2574-y) contains supplementary material, which is available to authorized users.

Antonio Iglesias

antonio.iglesias@roche.com

Pharma Research and Early Development (pRED), Pharmaceutical Sciences, Roche Innovation Center Basel, Basel, Switzerland

2 Pharma Research and Early Development (pRED), Pharmaceutical Sciences, Roche Innovation Center Munich, Munich, Germany

3 Division of Molecular and Systems Toxicology, Department of Pharmaceutical Sciences, University of Basel, Basel, Switzerland
Our results facilitate the use of Göttingen minipigs for assessment of human therapeutic antibodies in preclinical studies.

KEY WORDS antibody effector function · FcyR · Göttingen minipig $\cdot \lg G \cdot$ interaction map

$\begin{array}{ll}\text { ABBREVIATIONS } \\ \text { ADCC } & \text { Antibody-dependent cellular cytotoxicity } \\ \text { ADCP } & \text { Antibody-dependent cellular phagocytosis } \\ \text { FcYR } & \text { Fc gamma receptor protein } \\ \text { FCGR } & \text { Fc gamma receptor gene } \\ \text { FcR-Y } & \text { Fc receptor common gamma chain } \\ \text { chain } & \\ \text { HuCAL } & \text { Human combinatorial antibody library } \\ \text { IC } & \text { Immune complex } \\ \text { ITAM } & \text { Immunoreceptor tyrosine-based activation } \\ & \text { motif } \\ \text { NHP } & \text { Non-human primate } \\ \text { SPR } & \text { Surface plasmon resonance }\end{array}$

\section{INTRODUCTION}

Fc gamma Receptors (Fcyss) are a family of gylcoproteins expressed on the surface of leukocytes. They interact with the fragment crystallizable $(\mathrm{Fc})$ part of immunoglobulin $\mathrm{G}$ (IgG) antibodies and trigger a variety of effector functions including antibody-dependent cellular cytotoxicity (ADCG), antibody-dependent cellular phagocytosis (ADCP), antigen internalization and presentation, or inflammatory cytokine release (1). The set of Fc $\gamma$ Rs of most mammalian species consists of the high affinity Fc $\gamma \mathrm{RIa}(\mathrm{CD} 64)$, low affinity $\mathrm{F}_{\mathrm{c}} \mathrm{R}$ RIIa (CD32a) and FcyRIIIa (CD16), and the inhibitory FcyRIIb (CD32b) (2). Their cellular distribution and distinct affinities 
towards different IgG subclasses influence immune cell activation and control their effector functions upon IgG binding. Many novel therapeutic antibodies are IgG Fc engineered to alter the $\mathrm{Fc} \gamma \mathrm{R}$ binding in order to achieve enhanced activity via $\mathrm{ADCC}$ or $\mathrm{ADCP}$ or to reduce effector function-mediated toxicity $(3,4)$. Often, antibody effector functions are mediated upon interactions of low affinity Fc $\gamma \mathrm{Rs}$ with immune complexes (IC). For example, IC formed by bevacizumab binding to vascular endothelial growth factor (VEGF) can lead to Fc $\gamma$ RIIa-mediated platelet activation (5) and thrombosis in Fc $\gamma$ RIIa transgenic mice (6). Thus, it is very important to characterize the binding of free- and immune-complexed IgG to different $F_{c} \gamma R_{s}$ as this can dramatically influence safety and efficacy.

The porcine species (Sus scrofa) is an increasingly used animal model for biomedical research. In particular the Göttingen minipig has gained importance for preclinical safety and efficacy studies due to its high similarity to the human $(7,8)$. Also, the regulatory acceptance of the minipig as a relevant animal model for toxicological studies with biotherapeutics is growing (9). Furthermore, handling, housekeeping, and breeding of minipigs are much easier and cheaper than of non-human primates (NHP). So far, the Göttingen minipig has already been used for immunogenicity studies with infliximab and adalimumab (10). Presently, only few other minipig studies are performed with therapeutic antibodies (11) due to lacking knowledge about their pharmacology (12). Therefore, the importance of an adequate immunological characterization of the Göttingen minipig as a non-rodent species is widely recognized and promoted (13). The evaluation of the interactions of human therapeutic antibodies with porcine Fc $\gamma \mathrm{Rs}$ (poFc $\gamma R_{s}$ ) is a basic requirement for the use of the minipig in preclinical studies. So far, only functional binding studies of poFc $\gamma$ RIa and variants of poFc $\gamma$ RIIb to porcine total IgG have been reported confirming the conserved function of these receptors in pigs $(14,15)$. We have recently annotated the complete low affinity FCGR locus of the minipig including the localization of all $\mathrm{poF} \gamma \mathrm{R}$ genes and the description of the hitherto unknown poFc $\gamma$ RIIa (16). Binding and function of NHP or mouse FcyRs interacting with human IgG (huIgG) were studied to assess cross-reactivity and to estimate the translation potential of this preclinical species (17-19). To our knowledge, no extensive studies investigating the interactions of huIgG to poFc $\gamma \mathrm{Rs}$ were performed for any porcine species. Thus, the lacking knowledge of the binding properties of huIgG to poFc $\gamma \mathrm{R}_{\mathrm{s}}$ is still limiting the use of the minipig as a preclinical species with human therapeutic antibodies.

In the present work we hypothesized minipigs as a useful alternative for preclinical studies with therapeutic antibodies. Therefore, we qualitatively characterize the binding of human therapeutic antibodies to all Fc $\gamma \mathrm{Rs}$ in the minipig. Furthermore, we assessed the binding of free- and immunecomplexed huIgGl antibodies to poFc $\gamma \mathrm{Rs}$ in comparison to
huFc $\gamma$ Rs. The data provide first insights into possible effector functionalities of human immunoglobulins in preclinical studies in minipigs.

\section{MATERIALS AND METHODS}

\section{Recombinant FcyRs and Antibodies}

\section{Cloning}

Soluble Fc $\gamma$ Rs were designed as dimeric IgG Fc fusion proteins. Extracellular domains of poFc $\gamma$ RIa (UniProtKB: Q461Q0), poFcrRIIa (XM_021089520.1; 205Y), poFc $\gamma$ RIIb (UniProtKB: Q461P7), poFc $\gamma$ RIIb 1 (UniProtKB: B9VVN4), poFc $\gamma$ RIIIa (UniProtKB: Q28942) as well as huFc $\gamma$ RIa (UniProtKB: P12314), huFc $\gamma$ RIIa (UniProtKB: P12318 R131), huFc $\gamma$ RIIb (UniProtKB: P31994), huFc $\gamma$ RIIIa (UniProtKB: P08637 V158) were used. The sequences were back translated, codon optimized, and ordered as gene syntheses from GeneArt (Invitrogen). Subsequently they were cloned into an expression vector containing the signal peptide from mouse Ig heavy chain variable region, an Avi biotinylation tag (GLNDIFEAQKIEWHE, Avidity), a His6 tag, and an IgA protease cleavage site (VVAPP'AP). The vector also contained inert huIgG1 (PGLALA) Fc parts allowing the dimerization of the Fc $\gamma \mathrm{R}$ extracellular domains by the expression as Fc fusion proteins (20). These constructs are referred to as soluble Fc $\gamma$ Rs hereafter.

Full-length poFc $\gamma$ RIa (amino acids (aa) 16-346), poFc $\gamma$ RIIa (205Y; aa 46-274), poFc $\gamma$ RIIb (aa 46-297), poFc $\gamma$ RIIbl (aa 46-316), and poFc $\gamma$ RIIIa (aa 20-257) contained the human CD33 signal peptide (MPLLLLLPLLWAGALA) and a FLAG-tag (DYKDDDDK) at the N-terminus. Full-length huFc $\gamma \mathrm{Rs}$, the human Fc receptor common gamma chain (FcR- $\gamma$ chain), and the poFcR- $\gamma$ chain (UniProtKB: Q9XSZ6) were designed without the FLAG-tag.

PoIgGla (GenBank: U03781.1) and poIgG3 (GenBank: EU372658.1) heavy chain and Ig-kappa light chain (21) constant regions were coupled to the variable regions of the antihuman epidermal growth factor receptor 2 (HER2) antibody trastuzumab heavy chain (DrugBank: DB00072; aa 1-120) and Ig-kappa light chain (DrugBank: DB00072; aa 1-108), respectively. The correct transitions between the variable and the constant region of both antibodies were confirmed by molecular modeling. The recombinant antibodies contained the mouse $\mathrm{Ig}$ heavy chain $\mathrm{V}$ region 3 signal peptide (MGWSGIILFLVATATGVHS) and a C-terminal Avi biotinylation tag (GLNDIFEAQKIEWHE, Avidity). The resulting HER2 specific poIgG constructs are named poIgGla-HER2 and poIgG3-HER2 hereafter. 
The sequences of all constructs were verified prior to expression by DNA-sequencing (SequiServe and Microsynth).

\section{Expression}

Soluble Fc $\gamma$ Rs and poIgGs were expressed in human embryonic kidney 293F (HEK293F) suspension cells cultured in shaker flasks $\left(120 \mathrm{rpm}, 37^{\circ} \mathrm{C}, 5 \% \mathrm{CO}_{2}, 85 \%\right.$ humidity) using F17 expression medium supplemented with Pluronic and GlutaMAX (Gibco). Plasmids coding for Fc $\gamma$ Rs were transfected alone and poIgG heavy chains were co-transfected in equimolar ratio with plasmids coding for poIg-kappa light chain. Transient transfection was performed using 293free (Merck Millipore) premixed with OptiMEM (Gibco) and expression was enhanced by feeding and addition of valproic acid. The fed-batch culture was harvested by centrifugation 7 days after transfection and the supernatant was cleared by filtration.

Full length FcyRs were transiently expressed using the Expi293 system (Thermofisher). Suspension cells were seeded in 6 well-plates $\left(120 \mathrm{rpm}, 37^{\circ} \mathrm{C}, 5 \% \mathrm{CO}_{2}, 85 \%\right.$ humidity) and co-transfected with porcine or human Fc $\gamma$ Rs together with the related FcR- $\gamma$ chain in an equimolar ratio. The transfected cells were used $48 \mathrm{~h}$ post transfection.

\section{Purification and Analysis}

Soluble $\mathrm{Fc}_{\mathrm{c}} \mathrm{Rs}$ and poIgGs were purified by protein A (MabSelect SuRe, GE Healthcare) or, in the case of soluble Fc $\gamma$ RIa, by nickel (HisTrap HP, GE Healthcare) affinity chromatography using the ÄKTAexplorer 100 Air system (GE Healthcare). Soluble Fc $\gamma$ Rs were further purified by preparative size exclusion chromatography (SEG) using a HiLoad 26/ 600 Superdex prep grade column (GE Healthcare) with $20 \mathrm{mM}$ MOPS, $150 \mathrm{mM} \mathrm{NaCl}$, pH 6.0 as a running buffer.

Purified proteins were quantified on a Nanodrop spectrophotometer (Thermo Scientific) and analyzed under reducing and non-reducing conditions by capillary gel electrophoresis using Caliper LabChip (Perkin Elmer) or sodium dodecyl sulfate polyacrylamide gel electrophoresis (SDS-PAGE) with NuPAGE 4-12\% Bis-Tris gels in MES buffer followed by Coomassie staining (SimplyBlue, ThermoFisher). Aggregation and molecular weight of the $\mathrm{F}_{\mathrm{c}} \gamma \mathrm{R}$ products were determined by SEC coupled to Multi-Angle Light Scattering (MALS) using a Superdex 200 increase 10/300 GL column (GE Healthcare).

\section{Biotinylation}

Soluble poFc $\gamma$ Rs were biotinylated via the Avi-tag using the BirA Biotin-Protein Ligase standard reaction kit (Avidity). The biotinylation efficacy was assessed by liquid chromatography - mass spectrometry (LC-MS) after deglycosylation with PNGase F.

\section{Generation of FcyRIla and FcyRIla/b Specific Antibodies}

Purified soluble poFc $\gamma$ RIIa, poFc $\gamma$ RIIb, and poFc $\gamma$ RIII were sent to BioRad for the generation of bivalent Fab antibodies dimerized via alkaline phosphatase containing FLAG and His6 epitope tags (Fab-A-FH). Binders were selected via phage display method (CysDisplay $\left.{ }^{\circledR}\right)$ on BioRads Human Combinatorial Antibody Libraries (HuCAL). PoFc $\gamma$ RIIa/ Fc $\gamma$ RIIb cross-reactive HuCAL antibodies were generated by using poFc $\gamma$ RIIa as an antigen and poFc $\gamma$ RIII as a closely related antigen to prevent further cross reactivity. Similarly, poFc $\gamma$ RIIa specific antibodies were generated by using poFc $\gamma$ RIIb as a closely related antigen. All binders (HuCAL clones) were tested for their specificity by enzyme-linked immunosorbent assay (ELISA) coated with porcine Fc $\gamma$ RIIa, Fc $\gamma$ RIIb, and Fc $\gamma$ RIII.

\section{Immune Complex Generation}

IC were generated by overnight incubation at room temperature of the huIgGl therapeutic antibody bevacizumab (149 kDa; Roche) and its dimerized target VEGF165 (38 kDa, BioLegend), as described earlier (5). The antibody to target ratio of 1:2.5 was generated using $4 \mu \mathrm{M}$ bevacizumab and $10 \mu \mathrm{M}$ dimerized VEGF165, whereas the ratio of 1:0.5 was generated using $20 \mu \mathrm{M}$ bevacizumab and $10 \mu \mathrm{M}$ VEGF165, and the ratio of 1:0.1 using $20 \mu \mathrm{M}$ bevacizumab and $2 \mu \mathrm{M}$ VEGF165. IC formation was analyzed by SECMALS using a HPLC system equipped with a Superdex 200 increase 10/300 GL column (GE Healthcare), a TREOS laser light scattering detector, and a T-rEX differential refractometer (Wyatt Technology).

\section{Flow Cytometry}

\section{Phenotyping of FcyR Expression}

Fc $\gamma \mathrm{R}$ expression was assessed in whole blood of a Göttingen minipig sampled in K2EDTA Vacutainer tubes (BD) followed by treatment with lysing buffer (BD PharmLyse) to remove erythrocytes. Minipig blood cells were stained with PEconjugated antibodies against porcine GD16 (clone G7, BioRad) or unconjugated HuCAL antibodies against poFc $\gamma$ RIIa (clone AbD29332.1 “HuCAL32”), Fc $\gamma$ RIIa/b (clone AbD32591.1 "HuCAL91"), or the isotype control Fab-A-FH (clone AbD05930). The Fc $\gamma$ R expression of transfected HEK293F cells was assessed by staining using the abovementioned antibodies or the PE-conjugated antibodies against human CD64 (clone 10.1, BioLegend), human CD32 
(clone 3D3, BD), human CD16 (clone 3G8, BD), or FLAG tag (clone L5, BioLegend). Unconjugated antibodies were detected using the secondary $\mathrm{PE}$ conjugated goat $\mathrm{F}\left(\mathrm{ab} \mathrm{b}^{\prime}\right) 2$ anti-huIgG after washing with FACS buffer (Dulbecco's phosphate-buffered saline (DPBS, Gibco) containing 2\% bovine serum albumin (Sigma) and 0.1\% sodium azide (Sigma)). After washing with DPBS, dead cells were stained by the amine reactive Zombie Aqua dye (BioLegend) and the preparations were fixed using BD CellFIX. Events were acquired on BD LSRFortessa with BD FACSDiva software and data was further analyzed using FlowJo.

\section{Immune Complex Binding}

Binding of IC was assessed by flow cytometry analysis on whole blood of three Göttingen minipigs. Fresh blood was collected in Vacutainer tubes coated with K2EDTA (BD) and subsequently treated with erythrocyte lysis buffer (PharmLyse, BD) and washed with DPBS. The remaining blood cells were incubated with the amine reactive dye Zombie Aqua (BioLegend). After washing with FACS buffer, the blood cells were incubated in 96 well plates for $1 \mathrm{~h}$ at $4^{\circ} \mathrm{C}$ with different concentrations of bevacizumab, or bevacizumab-VEGF165 IC diluted in FACS buffer. Bevacizumab to VEGF165 ratios of 1:2.5, 1:0.5, and 1:0.1 were used. Unbound antibodies or complexes were removed by intensive washing with FACS buffer. PE-conjugated secondary goat $\mathrm{F}(\mathrm{ab}) 2$ antibodies against huIg-kappa (Biorad) were used to detect membrane-bound bevacizumab or IC. After another two washes with FACS buffer, 100'000 events were recorded on BD LSRFortessa with and the software BD FACSDiva. Data was further analyzed using FlowJo.

\section{SPR Experiments}

\section{IgG Capturing Setup}

The interaction of porcine or human $\mathrm{Fc} \gamma \mathrm{R}$ variants to porcine or human IgG anti-HER2 was analyzed using surface plasmon resonance $(\mathrm{SPR})$ on a Biacore T200 system (GE Healthcare). First, the extracellular domain of HER2 was immobilized at $\mathrm{pH} 4.5$ to $>3000$ response units (RU) on a CM5 chip using the amine coupling kit (GE Healthcare). Then, the HER2 specific antibodies trastuzumab (huIgG1, Roche), poIgGla-HER2 and poIgG3-HER2 were injected at a concentration of $100 \mathrm{nM}$ in PBS-P+ buffer $(\mathrm{GE}$ Healthcare) with a pulse of $30 \mathrm{~s}$ at a flow rate of $10 \mu \mathrm{l} / \mathrm{min}$ reaching capturing levels of $1000 \mathrm{RU}$. Soluble porcine or human Fc $\gamma$ Rs were prepared in solutions of $600,200 \mathrm{nM}$ and $66.7 \mathrm{nM}$ in PBS-P+ and applied at a flow rate of $30 \mu \mathrm{l} / \mathrm{min}$ for $90 \mathrm{~s}$. The dissociation phase was monitored for $600 \mathrm{~s}$ followed by regeneration of the surface by a 60 s and 20 s washing step with a $10 \mathrm{mM}$ Glycine $\mathrm{pH} 2.1$ at a flow rate of $10 \mu \mathrm{l} / \mathrm{min}$.
All experiments were performed in PBS-P+ pH 7,4 running buffer.

\section{FcyR Capturing Setup}

An alternative setup was used to compare binding of poFc $\gamma$ Rs to free- and immune-complexed huIgG1. Biotinylated soluble poFc $\gamma$ Rs were reversibly captured on a CAP chip using the standard Biotin CAPture reagent kit (GE Healthcare) at $\mathrm{pH}$ 7.4 PBS-P+. The capturing level of $\mathrm{Fc} \gamma \mathrm{R}$ variants reached 940-2543 RU. Porcine or human biotinylated Fc $\gamma$ R variants were prepared as solution of $200 \mathrm{nM}$ in PBS-P+ and captured with a pulse of $180 \mathrm{~s}$ at a flow rate of $5 \mu \mathrm{l} / \mathrm{min}$. Subsequently, human free- or immune-complexed $\mathrm{IgGl}$ were applied at a concentration of 600, 200 and $66.7 \mathrm{nM}$ in PBS-P+ at a flow rate of $30 \mu \mathrm{l} / \mathrm{min}$ for $120 \mathrm{~s}$. The dissociation phase was monitored for $600 \mathrm{~s}$. Then, the surface was regenerated by a $120 \mathrm{~s}$ washing step with the regeneration solution for the CAP chip (GE Healthcare) at a flow rate of $10 \mu \mathrm{l} / \mathrm{min}$.

\section{SPR Data Analysis}

The Biacore T200 software (GE Healthcare) was used to evaluate data from SPR experiments and to display binding curves. Interaction Map was used to separate heterogeneous binding into its individual 1:1 interactions with different kinetics. For this, data from SPR experiments were imported into TraceDrawer software (Ridgeview Instruments AB) and further processed with the Interaction Map program (Ridgeview Instruments $\mathrm{AB}$ ).

\section{RESULTS}

Interactions between IgG antibodies and their Fc receptors are of high complexity. To obtain a thorough characterization, we studied poFc $\gamma \mathrm{R}$ s as recombinant soluble proteins and expressed on the cell surface, as well as minipig blood cells that natively express Fc $\gamma$ Rs. Interactions of poFc $\gamma$ Rs were assessed with different free- or immune-complexed IgG antibodies and therapeutics.

\section{Binding of hulgG to poFcyRs}

The purpose of this experiment was to show qualitative binding of poFc $\gamma$ Rs to huIgG1, the most commonly used therapeutic human antibody isotype, by SPR. A highly sensitive assay is needed to detect weak interactions because low affinity Fc $\gamma$ Rs (Fc $\gamma$ RIIa, Fc $\gamma$ RIIb, and Fc $\gamma$ RIIIa) generally interact only weakly with free $\mathrm{IgG}$. Therefore, soluble porcine and human Fc $\gamma$ Rs were designed and used here as dimers of Fc $\gamma \mathrm{R}$ extracellular domains expressed as inert Fc fusion proteins. The dimeric structure provides an avidity effect and 
increases the molecular mass leading to higher sensitivity and therefore allowing a qualitative binding analysis (20). Transient expression in HEK293F cells and subsequent purification yielded soluble Fc $\gamma$ Rs of $>98 \%$ purity as determined by capillary gel electrophoresis or SDS-PAGE (not shown). PoFc $\gamma$ RIIb is exclusively composed of dimers, whereas poFc $\gamma$ RIa, poFc $\gamma$ RIIa, and poFc $\gamma$ RIIIa preparations additionally contained $32 \%, 74 \%$, and $77 \%$ aggregates, respectively, even after SEC purification (not shown). N-linked glycosylation of $\mathrm{F}_{\mathrm{c}} \gamma \mathrm{Rs}$ and $\mathrm{Fc}_{\mathrm{c}}$ fusion was effective in HEK293F cells as observed by PNGase F digestion followed by SDSPAGE (Fig. S1).

For the SPR binding analysis, the recombinant HER2 antigen was coated on a CM5 sensor chip and then allowed to capture trastuzumab, a HER2 specific huIgG1 therapeutic antibody, or HER2 specific poIgGs (Fig. la). To this purpose, the two most abundant isotypes in porcine blood, IgG la and IgG3 (22), were recombinantly expressed with HER2 specificity, and named poIgGla-HER2 and poIgG3-HER2, respectively. The soluble poFc $\gamma$ Rs were then allowed to bind human and porcine HER2-specific IgG (Fig. 1a).

Figure $1 \mathrm{~b}$ shows the maximum responses observed with huIgG1 in interaction with $600 \mathrm{nM}$ of porcine and human Fc $\gamma$ Rs. From this analysis we conclude that trastuzumab binds to most poFc $\gamma$ Rs in a similar magnitude as to huFc $\gamma$ Rs (Fig. 1b). A closer analysis of the sensorgrams generated using three concentrations of the soluble $\mathrm{F} c \gamma \mathrm{R}$ s permits a ranking of the binding strength among the different Fc $\gamma$ Rs (Fig. 1c). The sensorgrams show the response (RU) during association of the soluble Fc $\gamma$ Rs to antigen bound IgG until the steady state in the first $100 \mathrm{~s}$ followed by their dissociation. Among poFc $\gamma$ Rs, we identified poFc $\gamma$ RIa as the strongest binder for huIgG1 based on the quicker association and the slower dissociation, followed by poFc $\gamma$ RIIa. PoFc $\gamma$ RIIb is the weakest binder with the quickest dissociation whereas poFc $\gamma$ RIIIa did not bind huIgG1. However, the functionality of poFc $\gamma$ RIIIa was demonstrated through its binding to poIgG1 (Fig. 1c). A similar binding pattern was observed for huFc $\gamma \mathrm{R}_{\mathrm{s}}$ with huFc $\gamma$ RIa as the strongest binder of huIgGl followed by huFc $\gamma$ RIIa, Fc $\gamma$ RIIb, and huFc $\gamma$ RIIIa in a similar range. Comparing the orthologous porcine and human Fc $\gamma \mathrm{Rs}$, huIgG1 bound stronger to poFc $\gamma$ RIIa and poFc $\gamma$ RIIb but weaker to poFc $\gamma$ RIa and poFc $\gamma$ RIIIa as compared to the human orthologue (Fig. 1c). For all poFcyRs, except poFc $\gamma$ RIIIa, we observed a similar binding pattern of huIgG1 and poIgG1a-HER2. In contrast, poIgG3-HER2 showed only weak interactions to poFc $\gamma$ RIa and poFc $\gamma$ RIIa and no binding to poFc $\gamma \mathrm{RIIb}$ and poFc $\gamma \mathrm{RIII} a$. Vice versa, huFc $\gamma R_{s}$ did not notably bind to poIgGs (Fig. 1c). In sum, we found that poIgGl binds to poFc $\gamma \mathrm{RIa}>$ poFc $\gamma \mathrm{RIIa}>$ poFc $\gamma \mathrm{RIIb}$ and poFc $\gamma \mathrm{RIII}$ in a similar range, whereas huIgG1 binds to poFc $\gamma$ RIa $>$ poFc $\gamma$ RIIa $>$ poFc $\gamma$ RIIb $>>$ poFc $\gamma$ RIIIa.
The shape of the sensorgrams in Fig. 1c suggested complex multiple interactions contributing to $\mathrm{IgG}-\mathrm{Fc} \gamma \mathrm{R}$ bindings. Such heterogeneous interactions probably originate from different qualities of the individual Fcy Rs based on their integrity and the presence of aggregates. To assess the contribution of quality issues leading to heterogeneous interactions, we also analyzed the huIgG1 binding data using the Interaction Map method (Fig. 1d). It allows the decomposition of time-resolved binding curves into separate interactions with unique combinations of association rates $\mathrm{k}_{\mathrm{a}}\left[\mathrm{M}^{-1}, \mathrm{~s}^{-1}\right]$ and dissociation rates $\mathrm{k}_{\mathrm{d}}\left[\mathrm{s}^{-1}\right]$, contributing to the total binding (23). Therefore, the Interaction Map analysis allows addressing the heterogeneity of $\mathrm{IgG}-\mathrm{Fc} \gamma \mathrm{R}$ interactions. The resulting on-off plots display single interactions by their dissociation $\left(\log \left(\mathrm{k}_{\mathrm{d}}\right), \mathrm{x}\right.$-axis $)$ and association $\left(\log \left(\mathrm{k}_{\mathrm{a}}\right)\right.$, $\mathrm{y}$-axis) values colored according to their contribution to the total binding (Fig. 1d). Because no interaction of trastuzumab was observed with poFc $\gamma$ RIIIa, this data could not be analyzed by Interaction Map. For the other $\mathrm{F}_{\mathrm{C}} \mathrm{R} \mathrm{R}$, this analysis disclosed multiple interactions involved in the binding of huIgGl to poFc $\gamma$ RIa, poFc $\gamma$ RIIa, and huFc $\gamma$ RIIIa (Fig. 1d). Interestingly, the FcyRs with the most obvious multivalent binding properties were the preparations with the highest proportion of aggregates. Therefore, one spot originates from the bivalent functional binding, whereas the other spot reflects the binding to aggregates contained in the preparation. Because aggregates reformed after SEC purification, it was not possible to identify which interaction was responsible for the functional binding. The correct binding kinetics of these $\mathrm{F}_{\mathrm{c}} \gamma \mathrm{Rs}$ must be a mixture of the observed interactions. Therefore, we refrain from reporting affinities based on one 1:1 kinetic. Additionally, it was shown by other authors that IgG-Fc $\gamma$ R interactions do not depend on only one $1: 1$ kinetic and are strongly influenced by the experimental setup and other factors, such as Fc $\gamma \mathrm{R}$ glycosylation (24).

In addition to poFc $\gamma \mathrm{RIIb}$, another isoform named poFc $\gamma$ RIIbl has been reported having a 19 amino acid inframe insertion in the cytoplasmic domain. Apart from the signal sequence, these variants also differ by one polymorphism in the extracellular domain 1 and two polymorphisms in the extracellular domain 2 (the latter are marked in yellow in Fig. S2) (25). We directly compared these two polymorphic variants in SPR regarding binding to porcine or human IgG and found no differences in IgG isotype selectivity and negligible stronger binding of the poFc $\gamma$ RIIbl variant (Fig. S3).

\section{Binding of hulgG I to poFcyRs on Cells}

Next, we addressed binding of free huIgGl to poFc $\gamma \mathrm{Rs}$ in a more biological system with transfected HEK293F cells expressing surface-anchored Fc $\gamma$ Rs. Due to the lack of available antibodies specific for poFc $\gamma \mathrm{Rs}$, we also generated phagedisplay based recombinant antibodies with specificity for poFc $\gamma$ Rs using the HuCAL technology. The specificity of 
a

Soluble huFcyR
or soluble poFcyR
600 nM, 200 nM, 66.7 nM

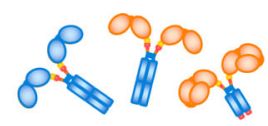

hulgG-HER2
or polgG-HER2

$\approx 1000 \mathrm{RU}$

HER2 ECD

on CM5 chip
企

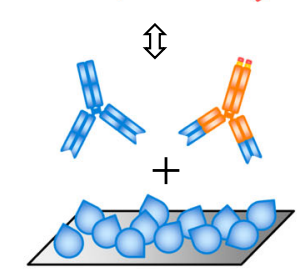

b

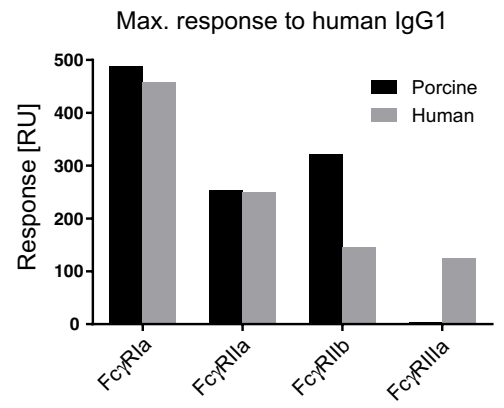

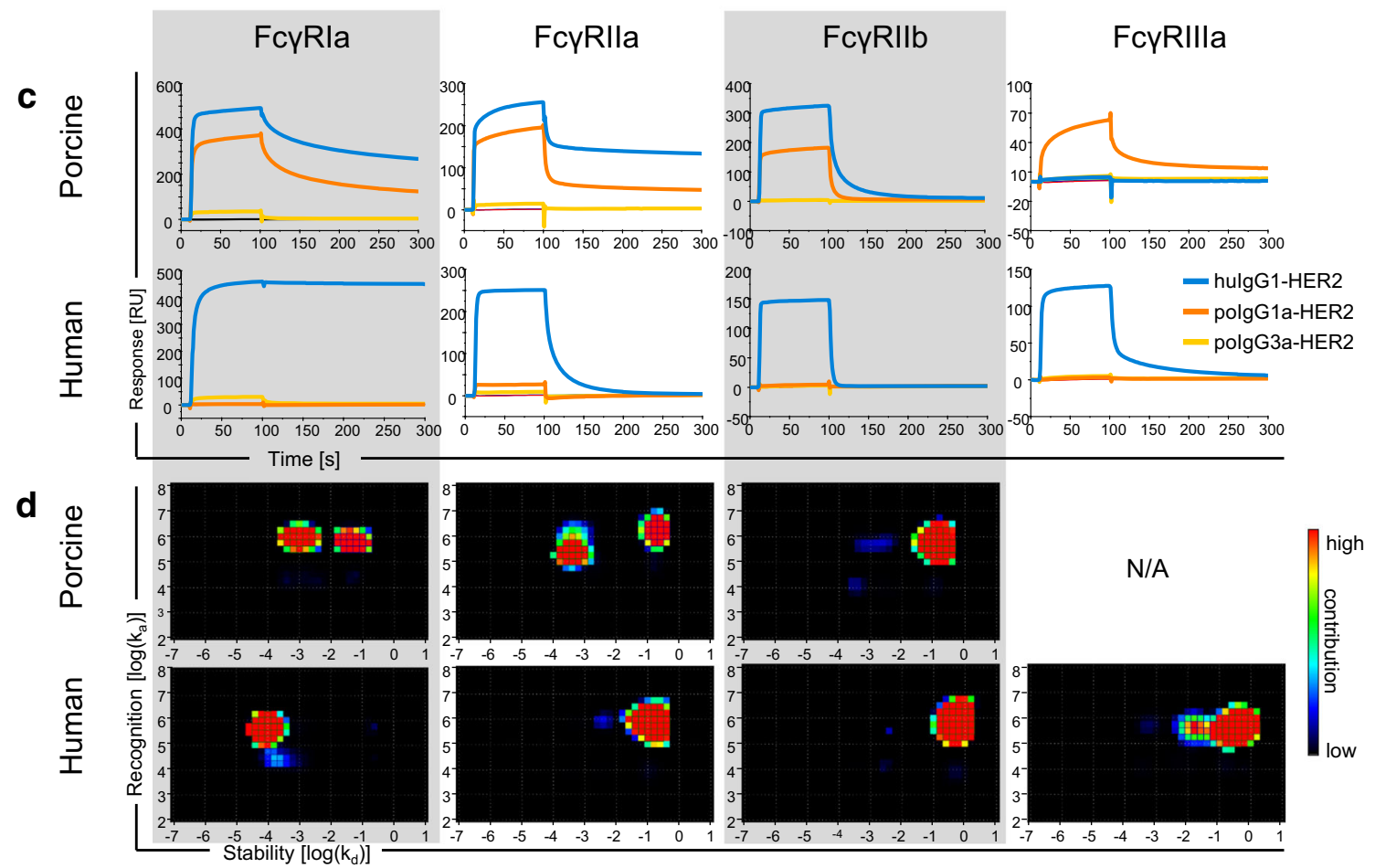

Fig. I SPR binding analysis of soluble FcyRs to IgG. (a) Scheme depicting the assay setup. First, extracellular domains of HER2 were coated on a CM5 sensor chip. Then, HER2 specific human (blue structures) and porcine (orange structures) antibodies were captured on different flow cells. Their interactions with soluble porcine or human FcyRs were measured. The drawing shows low affinity FcyRs with two and the high affinity FcyRla with three extracellular domains (oval shapes). (b) The graph shows the maximum response of $600 \mathrm{nM}$ porcine (black bars) and human (grey bars) FcyRs obtained with hulgGI. (c) Real-time sensorgrams from SPR analysis. Interaction of IgG to poFcyRs is shown in the upper row and to huFcyRs in the lower row whereas the respective FcyRs are named above. Binding of 600 nM soluble FcyRs to trastuzumab (hulgG I, blue line), polgG l a-HER2 (orange line), and polgG3-HER2 (yellow line) is shown. Only the highest concentration of the titration with 600, 200, and 66.7 nM of soluble FcyRs is shown for clarity. (d) Interaction Map analysis resulting from trastuzumab binding to all concentrations of porcine and human FcyRs is shown in the upper and lower row, respectively. The binding is separated in several parallel interactions with unique kinetics, as displayed by spots on a graph with $k_{d}$ on the $x$-axis and $k_{a}$ on the $y$-axis. The heat map is a measure of the contribution from red $=$ high to blue $=$ low of each interaction to the total binding. No interaction was detected with poFcyRllla; therefore, it could not be analyzed (N/A).

these HuCAL antibodies was also assessed using cell surfaceanchored Fc $\gamma$ Rs.

Full length poFc $\gamma$ Rs with extracellular FLAG tags encoded at the N-terminus were transiently expressed on HEK293F cells. However, full-length huFc $\gamma$ Rs were expressed without FLAG tags. The data shown in Fig. 2a demonstrate expression of all porcine and human FcyRs on the cell surface of HEK293F cells. The expression of huFc $\gamma$ Rs and of poFc $\gamma$ RIIIa was characterized via commercial Fc $\gamma$ R-specific antibodies whereas a FLAG tag specific antibody was used to characterize the expression of all poFc $\gamma$ Rs. The expression of
poFc $\gamma$ RIIa was further demonstrated with the antibody clone HuCAL32 that binds specifically to this $\mathrm{F} \gamma \mathrm{R}$ in contrast to the antibody clone HuCAL91 that is cross-reactive to the closely similar Fc $\gamma$ RIIb (Fig. 2a).

Binding to Fc $\gamma$ Rs expressed on HEK293F cells was then assessed using different concentrations of bevacizumab, a huIgG1 anti-VEGF therapeutic antibody displaying similar SPR binding to poFcyR as trastuzumab (not shown). Cell bound bevacizumab was detected via flow cytometry using goat $\left.\mathrm{F}(\mathrm{ab})^{\prime}\right) 2$ anti-huIg-kappa secondary antibody. The results show a concentration-dependent binding of bevacizumab to 

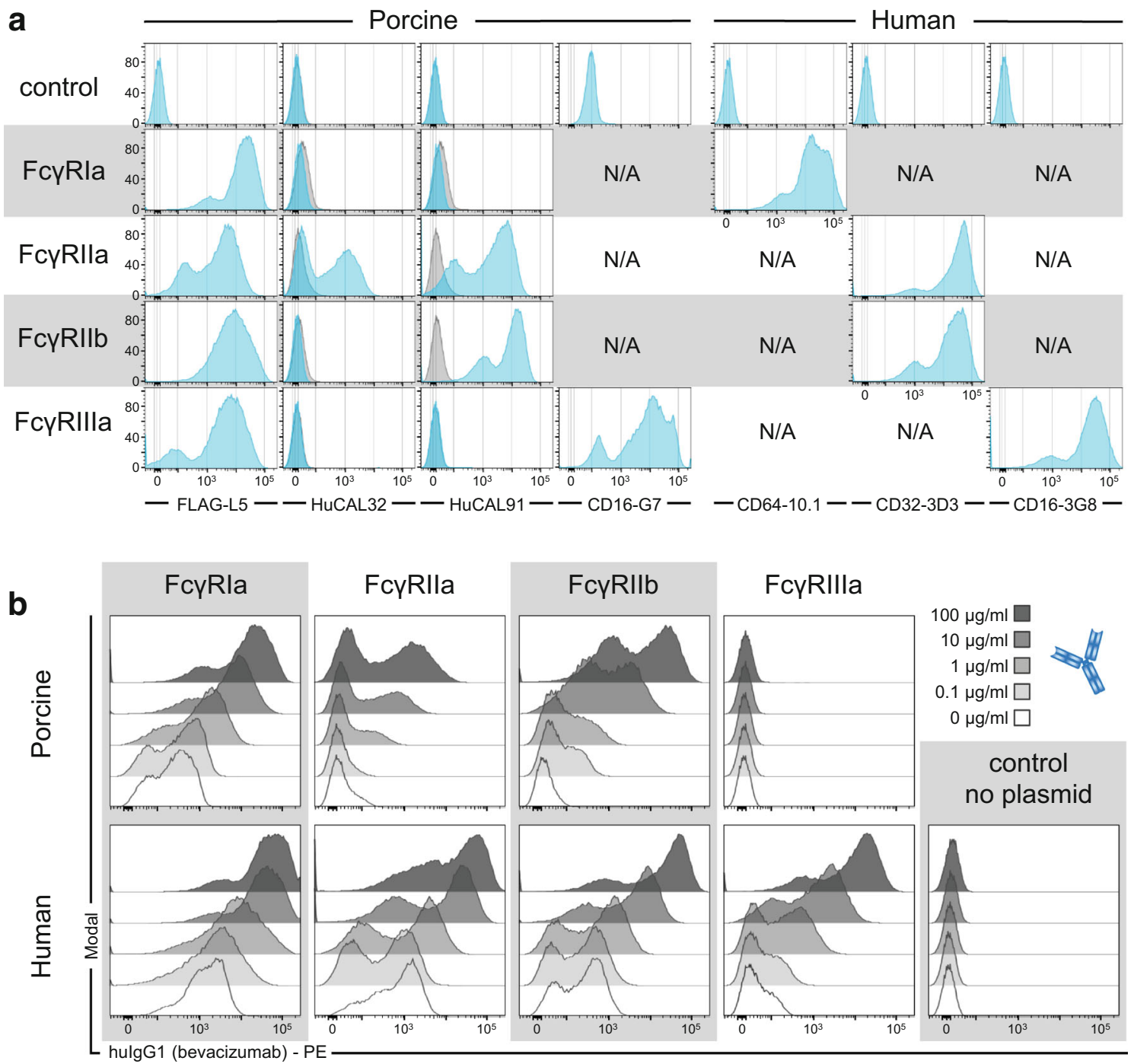

Fig. 2 Binding of bevacizumab (hulgGI) to FcyRs transiently expressed on HEK293F cells. (a) HEK293F cells expressing the indicated porcine (left panel) and human (right panel) FcyRs were analyzed by flow cytometry using the antibodies indicated below each column. HEK293F cells transfected without plasmid served as a negative control (first row). Blue histograms show binding of the antibody to the respective cells whereas N/A indicates combinations of antibodies and FcyRs that were not analyzed. Overlaid grey histograms display the staining with the HuCAL control antibody. (b) Bevacizumab was titrated and incubated with HEK293F cells expressing the indicated FcyR. After intense washing, FcyR-bound IgG was stained with PE-conjugated goat F(ab')2 anti-hulg-kappa secondary antibody and analyzed by flow cytometry. Stacked histograms show binding of increasing concentrations with increasing intensity: no bevacizumab (open histogram), $0.1 \mu \mathrm{g} / \mathrm{ml}$ (shaded in light grey), I, 10, and $100 \mu \mathrm{g} / \mathrm{ml}$ (shaded in dark grey).

porcine (except for poFcyRIIIa) and human FcyRs (Fig. 2b). From these data we conclude that surface-anchored poFc $\gamma$ RIa, IIa and IIb, but not poFc $\gamma$ RIIIa can bind by free huIgG1.

\section{Binding of hulgG I Immune Complexes to poFcyRs}

Human low affinity $F c \gamma R s$ mediate their functions rather via interaction with IC in contrast to free IgG (26). The increase in avidity compensates for the low affinity and allows stable binding to the IC ultimately leading to activation of the $\mathrm{F}_{\mathrm{c}} \mathrm{R}$ s. In order to assess binding of poFc $\gamma$ Rs to huIgGl IC we performed SPR experiments with pre-formed IC of bevacizumab and its dimeric target antigen VEGF.
To generate physiological IC, bevacizumab was coincubated with VEGF and the resulting complexes were studied by SEG-MALS. The stoichiometric ratio of one antibody together with an excess of five VEGF dimers resulted in large IC without remaining free IgG where the majority of complexes is composed of three or more antibodies (Fig. 3a). For the measurement of their binding profiles in comparison to free $\mathrm{IgG}$, all poFc $\gamma$ Rs were biotinylated and coated on the sensor chip (Fig. 3b). For every Fc $\gamma$ R, two different capturing densities were assayed. The densities of Fc $\gamma$ RIa (940RU), Fc $\gamma$ RIIa (1020RU), and Fc $\gamma$ RIIb (2543RU) were found to give best results probably reflecting their different affinities to huIgG1. We, however, did not achieve sufficient biotinylation of poFc $\gamma$ RIIIa to increase its capturing density above 
a

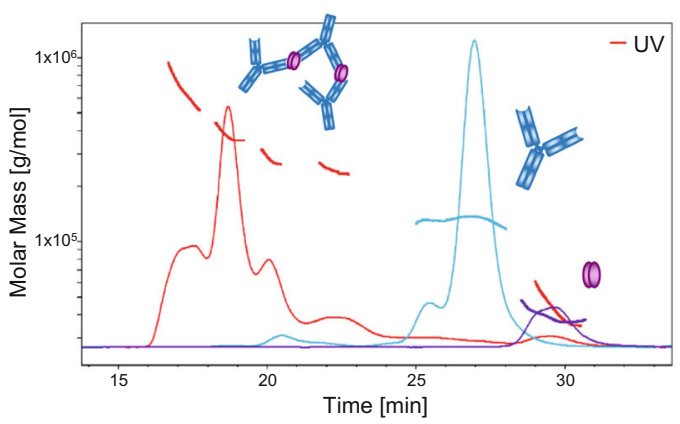

b

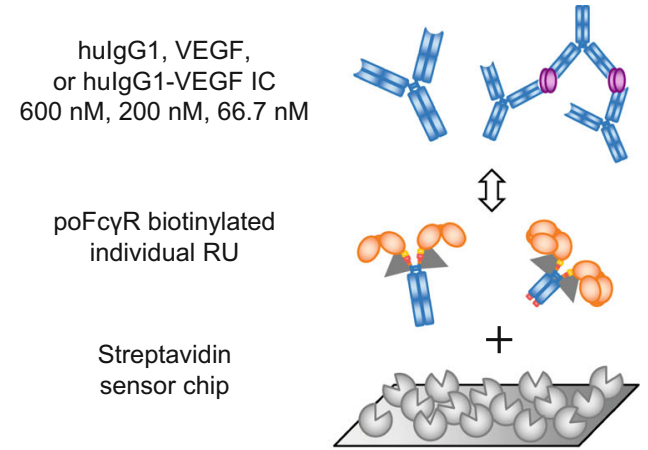

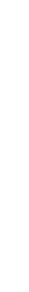

C
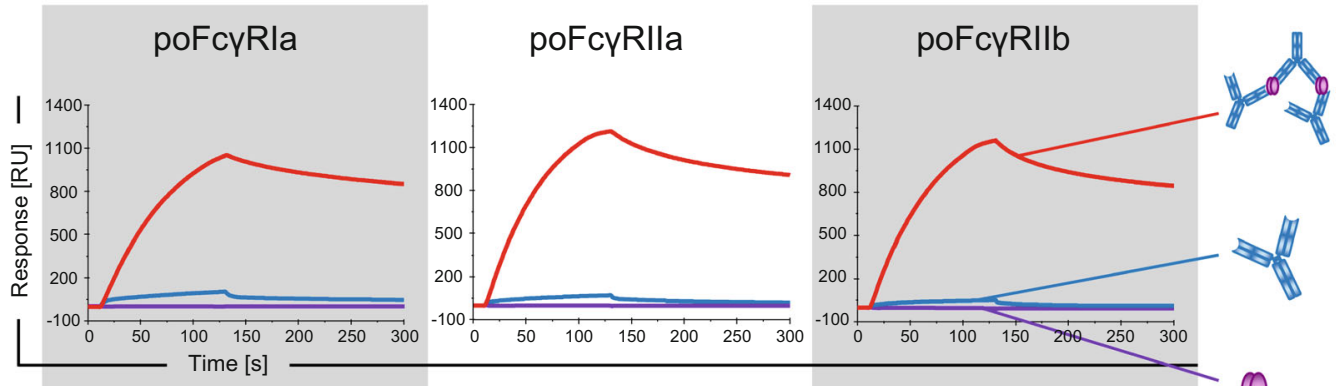

d
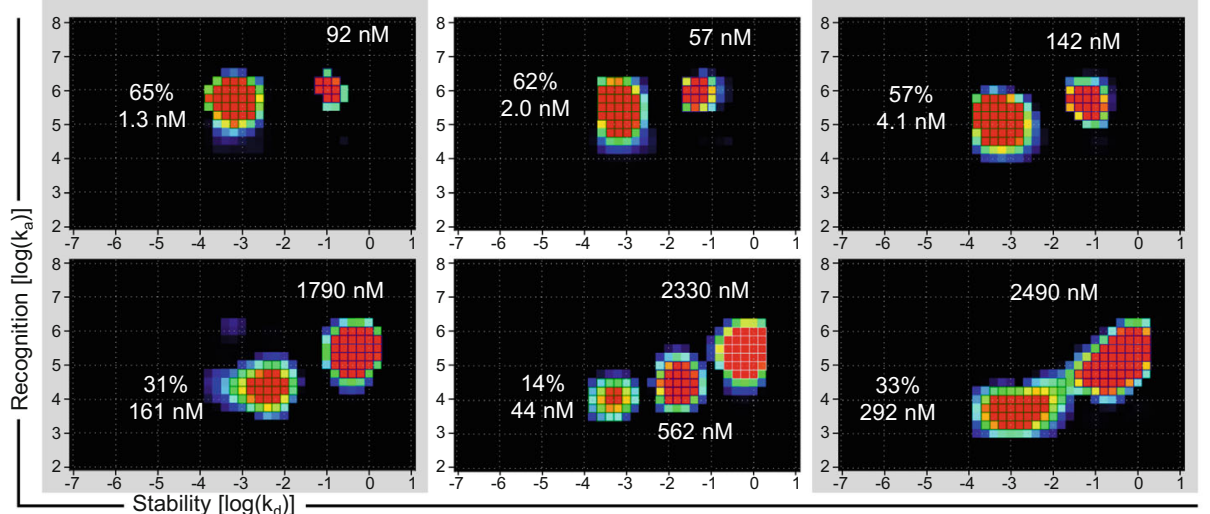

Fig. 3 Comparison of free bevacizumab and IC by binding to poFcyRs using SPR. (a) SEC-MALS analysis shows the molecular weight of free bevacizumab (blue line), VEGF (purple line), and complexes formed by bevacizumab and VEGF in a molar ratio of I:5 (red line). (b) Biotinylated (grey triangles) soluble poFcyRs were captured with different densities on a streptavidin senor chip. Interactions with free bevacizumab (blue) and IC with VEGF dimers (purple ovals) were measured by SPR. Three different concentrations of IC and free hulgG I with the same amount of IgG were assayed (600, 200, 66.7 nM). PoFcyRIIla was excluded from this experiment due to insufficient biotinylation. (c) SPR sensorgrams resulting from binding of the above indicated FcyR to the highest concentration of VEGF (purple line), bevacizumab (blue line), and IC (red line) are shown. (d) Binding curves from panel C were resolved by the Interaction Map method. Binding of hulgG I IC to the FcyR indicated above each column is shown in the upper row and binding of free hulgG $\mathrm{I}$ is shown below. The equilibrium binding constant $K_{D}[\mathrm{nM}]$ is indicated next to each major interaction spot and its contribution [\%] to the total binding is indicated for the spot with the highest affinity.

54RU, and was therefore excluded from the experiment. Subsequently, 600, 200, and $66.7 \mathrm{nM}$ of free huIgG1 or IC formed with the same amount of huIgG1 were used to assess the binding strength (Fig. 3b).

The sensorgrams in Fig. 3c show a strong increase in the maximum response and a more stable interaction with $\mathrm{IC}$ compared to free huIgG1 in all poFc $\gamma$ Rs. We again analyzed the SPR binding data with the Interaction Map method (Fig. 3d) first, because the observed maximum response largely depends on the size of the bound complex and second, because we expect avidity based heterogeneous IC-Fc $\gamma \mathrm{R}$ interactions. Using this setup, we observed two to three interactions contributing to the binding of poFc $\gamma$ Rs to free huIgG1, probably resulting from partial activity of the soluble Fc $\gamma$ Rs (Fig. 3d). The contribution of all interactions shifted towards lower $\mathrm{k}_{\mathrm{d}}$ and higher $\mathrm{k}_{\mathrm{a}}$ values and ultimately towards a stronger binding comparing free bevacizumab to IC. Additionally, Fig. 3d shows a shift of the individual interactions towards a higher affinity. For poFc $\gamma$ RIa, for example, the higher affinity interaction shifts the center of the spot to a $5 \mathrm{x}$ longer half-life (shift towards lower $\mathrm{k}_{\mathrm{d}}$ ) as seen in Fig. 3d and evaluated by the interaction map software, a 10x quicker 
association (shift towards higher $\mathrm{k}_{\mathrm{a}}$ ), and therefore a $100 \mathrm{x}$ enhanced affinity $\left(\mathrm{K}_{\mathrm{D}}=\mathrm{k}_{\mathrm{d}} / \mathrm{k}_{\mathrm{a}}\right)$ comparing free huIgG1 to IC.

Additionally, its contribution increases from $31 \%$ to $65 \%$. On the other hand, the low affinity interaction decreases its contribution from $50 \%$ to $16 \%$ (Fig. 3d, left plots). For poFc $\gamma$ RIIa and poFc $\gamma$ RIIb the changes in affinity from free huIgG1 to IC are comparable to those for poFc $\gamma$ RIa. This data clearly demonstrates a stronger and more stable interaction of huIgG1 IC with poFc $\gamma$ Rs than with free huIgG1 based on avidity effects. IC binding is a prerequisite for effector functions triggered by huIgG in minipigs.

\section{Binding of hulgG I IC to Minipig Blood Cells}

Next, we studied interactions of free huIgGl (bevacizumab) to blood cells of Göttingen minipigs that natively express poFc $\gamma$ Rs. Free huIgG1 and different preparations of IC were titrated and co-incubated with minipig whole blood for $1 \mathrm{~h}$ at $4^{\circ} \mathrm{C}$ in FACS buffer containing sodium azide to prevent internalization. Bound antibodies or IC were stained using goat $\mathrm{F}\left(\mathrm{ab}^{\prime}\right) 2$ anti-huIg-kappa secondary antibody and analyzed by flow cytometry. The different blood cell subsets were gated from forward and side scatter (FSC/SSC) of viable single cells without including specific cell surface markers due to limited availability of specific antibodies, fluorochromes, and cross-reactivity. The gating strategy and identity of the different cell types of the minipig blood is shown in Fig. S4. The Fc $\gamma \mathrm{R}$ expression in the respective minipig blood cells was assessed in separate stainings and shown in Fig. 4a. PoFc $\gamma$ RIIa (stained by HuCAL32) was found to be expressed on platelets and a sub-population of eosinophils. The poFc $\gamma \mathrm{RII} / \mathrm{b}$ cross-reactive antibody (HuCAL91) additionally stained a large proportion of monocytes that are thus thought to express poFc $\gamma$ RIIb. Monocytes, neutrophils, and eosinophils all express poFcyRIIIa. Furthermore, small lymphocyte subsets, such as $\mathrm{B}$ cells and NK cells are known to express poFcyRIIb and poFc $\gamma$ RIIIa, respectively and monocytes are known to express poFc $\gamma$ RIa $(16,27)$. The poFc $\gamma$ RIa expression beyond lymphocytes and monocytes is largely unknown and can thus not be excluded on platelets, neutrophils, and eosinophils. Histograms in Fig. 4b show the binding of $0.1 \mu \mathrm{g} / \mathrm{ml}$ free huIgG1 and the same amount of huIgG1 complexed using different ratios of VEGF165 to the different minipig blood cell subsets. The antibody (bevacizumab, Bev) to target (VEGF) ratio of 1:2.5 yielded the largest IC without free huIgG1 whereas IC generated in the ratio of 1:0.5 and 1:0.1 were smaller and contained more free huIgG1 (Fig. S5). Here, we observed that large IC showed enhanced binding to all platelets and most monocytes versus smaller IC and free huIgG1. Furthermore, large IC resulted in the strongest shift of neutrophils and eosinophils, even though the MFI was lower than in platelets and monocytes. A small subpopulation of lymphocytes also bound large IC better than small IC and free huIgG1 (Fig. 4b). As in the histograms, it is apparent from the titration of all IC preparations in the blood of three Göttingen minipigs that free- and immune-complexed huIgGl exhibit the strongest binding to platelets, followed by monocytes, eosinophils, neutrophils and lastly lymphocytes (Fig. 4c). The titration shows that in particular the largest IC strongly bind to poFc $\gamma$ R-expressing cell types at the lowest concentrations translating to the highest affinity. Vice versa, preparations with limited VEGF165 or without VEGF165 (huIgG1 alone) require higher concentrations to bind to poFcyR-expressing cell types, translating to lower affinities. VEGF165 did not bind to minipig blood cells at the concentration used to generate the largest IC (ratio 1:2.5) containing $10 \mu \mathrm{g} / \mathrm{ml}$ huIgGl. The strongest differences between free-and immune-complexed huIgGl were observed in platelets and monocytes. Neutrophils and eosinophils also bound IC stronger than free huIgG1, however the maximum percentage of positive cells in these cell types were lower and the individual differences were more pronounced leading to a higher standard deviation (Fig. 4c).

\section{DISCUSSION}

The use of the Göttingen minipig in preclinical studies with therapeutic antibodies is limited by the lack of knowledge on the expected pharmacology for the translatability of corresponding findings to the human. The pharmacology of antibodies with active $\mathrm{Fc}_{\mathrm{c}}$ parts often depends on effector mechanisms mediated by interaction with Fc $\gamma$ Rs. The aim of this study was to assess the binding properties of huIgG1 therapeutic antibodies to $\mathrm{poF} c \gamma \mathrm{Rs}$ which is a prerequisite for the consideration of the minipig for preclinical safety and efficacy studies with therapeutic antibodies.

The present study demonstrates that poFc $\gamma$ Rs bind human therapeutic antibodies of the IgG1 isotype. The binding properties of the poFc $\gamma$ RIa, poFc $\gamma$ RIIa, and poFc $\gamma$ RIIb closely resemble those of the human orthologues albeit some differences were identified. Importantly, poFc $\gamma$ RIIIa was shown not to bind huIgGl antibodies. Similar to huFc $\gamma R s$, all poFc $\gamma R s$ except poFc $\gamma$ RIIIa were shown to bind IC composed of huIgG1 with a higher affinity than free huIgG1. Especially, monocytes, eosinophils, platelets and a subset of lymphocytes of minipig blood showed enhanced binding to human IC.

The poFcyRIa was cloned by Zhang, Qiao (15) and shown to bind poIgG. Here we also demonstrate that poFc $\gamma$ RIa, similar to its human orthologue, strongly binds huIgG1 (28). The high affinity interaction of huFc $\gamma$ RIa is supposed to be mediated by a hydrophobic pocket for Leu235 within the Fc part of huIgG (29). The same pocket was also identified in poFc $\gamma$ RIa supporting its high affinity for huIgG1 (Fig. S2). Nevertheless, we found differences between the two species in residues forming $\mathrm{H}$ bonds (Lys128, Ala143 in Fig. S2). This could explain the weaker 


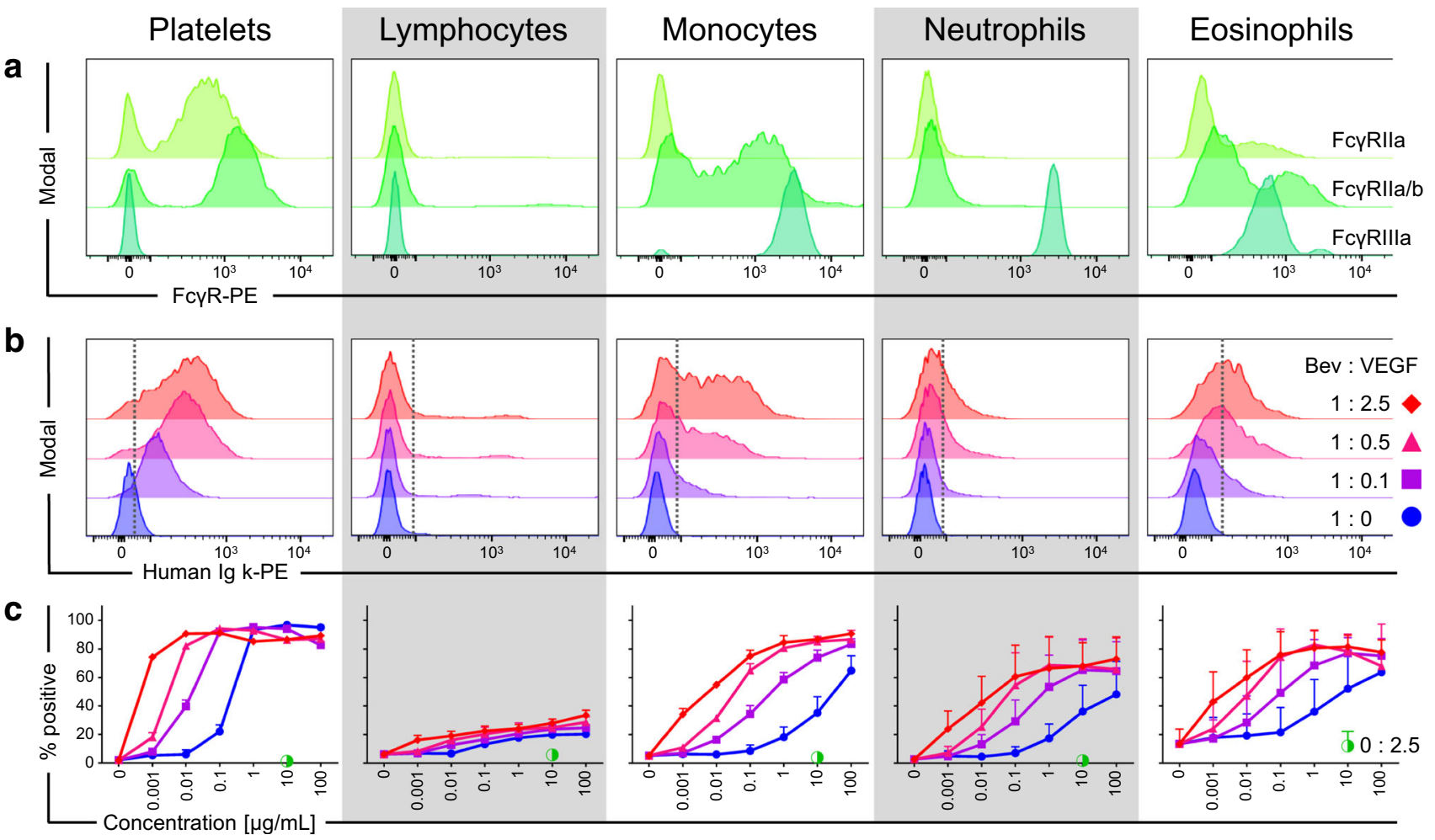

Fig. 4 Binding of free hulgG I (bevacizumab) and IC to minipig whole blood in comparison to the FcyR expression. FcyR expression and hulgG binding was assessed by flow cytometry in whole blood of Göttingen minipigs. The cell types were gated from single live cells by their FSC and SSC properties as described in detail in Fig. S4. (a) Histograms show the expression of poFcyRlla (HuCAL32, light green histogram), poFcyRlla/b (cross reactive HuCAL9I, green histogram) and poFcyRIlla (clone G7, dark green histogram) in platelets, lymphocytes, monocytes, neutrophils and eosinophils (from left to right). (b) Stacked histograms show the binding of $0.1 \mathrm{gg} / \mathrm{ml}$ free hulgGI (blue) and the same amount of hulgG I complexed using 0.1 parts of VEGFI65 (purple), 0.5 parts of VEGFI 65 (magenta), or 2.5 parts of VEGFI 65 to the different minipig blood cell subsets. The dotted line represents the gate separating PE-negative (left) from PE-positive (right) events. (c) Graphs show the percentage of $\mathrm{PE}$-positive cells with increasing concentrations of free- (blue circles) and immune-complexed bevacizumab with concentrations ranging from I00 to $0.001 \mu \mathrm{g} / \mathrm{ml}$ of hulgGI and a control containing $0 \mu \mathrm{g} / \mathrm{ml}$ bevacizumab or IC. IC generated by the following antibody to target ratios are displayed: I:0.I (purple squares), 1:0.5 (magenta triangles), 1:2.5 (red diamonds), and VEGF alone (half-filled green circle). Error bars represent the standard deviation within one representative experiment using three minipigs. Multiple experiments with IC (ratio I:2.5) using a total of seven minipigs led to similar results.

binding of huIgGl to poFc $\gamma$ RIa compared to huFc $\gamma$ RIa. The observed difference concerning the heterogeneity of interactions probably results from avidity effects caused by Fc $\gamma R$ aggregation. PoFc $\gamma$ RIa is, like its human orthologue, expressed on monocytes in peripheral blood of minipigs (16). A fraction of minipig monocytes binds huIgG1 IC already at low concentrations, possibly mediated by poFc $\gamma$ RIa, although poFc $\gamma$ RIIb and poFc $\gamma$ RIIIa cannot be excluded since these Fc $\gamma$ Rs are also expressed on monocytes. The enhanced binding of complexed versus free huIgG1 to poFc $\gamma$ RIa was confirmed by SPR. Notably, we did not observe a strong staining with free huIgG1 as it could be expected for binding to poFc $\gamma$ RIa. A gradual dissociation of free $\mathrm{IgGl}$ from huFc $\gamma \mathrm{RIa}$ is believed to allow capturing small IC or sparsely opsonized large complexes (30). Our results suggest a similar role of poFc $\gamma$ RIa by the observation of the strong IC binding (Fig. 3c and d) and weak staining of poFc $\gamma$ RIa expressing monocytes with low concentrations of free huIgG (Fig. 4b).
Fc $\gamma$ RIIa is known as a low affinity receptor signaling through an integrated intracellular immunoreceptor tyrosine-based activation motif (ITAM) in the human. However, orthologues to FcyRIIa in the mouse, cattle and pig, for example, are lacking this integrated ITAM and require $\mathrm{FcR} \gamma$-chain interactions for signaling (16,31). In terms of binding, we found that Fc $\gamma$ RIIa of both species bind huIgG1 (Fig. 1). Conserved tryptophan residues Trp104 and Trp127 forming the "Trp sandwich" of Fc $\gamma$ Rs that interacts with Pro329 of IgG Fc parts could enable such cross-species interactions (Fig. S2) (32). Interestingly, trastuzumab bound to poFc $\gamma$ RIIa with an increased stability compared to huFc $\gamma$ RIIa (Fig. 1). HEK293F cells expressing porcine and human Fc $\gamma$ RIIa showed similarities in binding properties to bevacizumab as observed by the concentration-dependent increase of binding (Fig. 2b). The differences in background and the intensity of the positive population possibly originate from the lower expression of poFc $\gamma$ RIIa compared to huFc $\gamma$ RIIa on HEK293F cells (Fig. 2). A high avidity binding of IC to 
poFc $\gamma$ RIIa was observed by SPR as described for human low affinity receptors (Fig. 3c and d) (33). This was also reflected in the strong binding of IC to minipig platelets expressing highest levels of FcyRIIa (Fig. 4a). Yet, platelets were also the strongest binders of free bevacizumab. This could be explained by the increased affinity of poFc $\gamma$ RIIa in relation to huFc $\gamma$ RIIa. The increased affinity could further lead to an enhanced sensitivity of the minipig for Fc $\gamma$ RIIa binding and ultimately to an overprediction of Fc $\gamma$ RIIa-mediated toxicities in preclinical studies. Lau, Gunnarsen (34) observed platelet aggregation and toxicities in domestic pigs treated with mouse IgG2b antiporcine $\mathrm{CD} 14$ (clone MIL2) possibly due to $\mathrm{Fc} \gamma \mathrm{R}$ activation and complement binding. A recombinant huIgG2/4 antiporcine CD14 antibody (rMIL2) however, did not induce aggregation probably due to abolished Fc $\gamma \mathrm{R}$ or complement binding in pigs.

The inhibitory low affinity Fc $\gamma \mathrm{RIIb}$ is mainly expressed on human $\mathrm{B}$ cells, dendritic cells (DC), and tissue macrophages and is an important regulator of immune responses (1). Here, we report enhanced binding of poFc $\gamma \mathrm{RIIb}$ to trastuzumab in comparison with huFcyRIIb (Fig. 1). The Interaction Map analysis shows a homogeneous interaction for the porcine and human FcyRIIb. Therefore, we conclude that the three times increased affinity is not assay dependent. This finding is also in concordance with Macaca nemestrina Fc $\gamma \mathrm{RIIb}$ showing enhanced huIgG1 binding (32). Fc $\gamma$ RIIb of macaques and cyno have residues His131 at the location of the huFcyRIIa His131Arg polymorphism and Met132 nearby. These residues were shown to account for the increased binding while huFc $\gamma$ RIIb has Arg131 and Ser132 in these positions. In poFc $\gamma \mathrm{RIIb}$, however, we identified residues Tyr and Val at the corresponding positions probably influencing the binding in another way (Fig. S2). Triggering of the inhibitory huFc $\gamma$ RIIb in macrophages and dendritic cells can counteract the effects mediated by activating Fc $\gamma \mathrm{Rs}$ (35). Enhanced binding of huIgGl to poFc $\gamma \mathrm{RIIb}$ could therefore enhance the threshold for cell activation and result in a more tolerogenic milieu in inflamed tissue, thus leading to an overestimated efficiency of immunosuppressive therapeutic antibodies in minipigs. Simultaneously, treatment with therapeutic huIgGl antibodies could lead to enhanced risk for pneumococcal peritonitis while reducing pathological immune stimulation due to reduced reactivity of macrophages $(36,37)$. Furthermore, Fc $\gamma$ RIIb expressed on B cells plays an important role in maintenance of peripheral tolerance (38). Thus, the stronger binding of huIgGl antibodies to poFc $\gamma \mathrm{RIIb}$ on $\mathrm{B}$ cells could lead to enhanced tolerance and hence to underestimation of immunogenicity concerns.

From all studied receptors, the most pronounced differences between minipig and human were observed for Fc $\gamma$ RIIIa. In humans, Fc $\gamma$ RIII is a low affinity activating receptor binding huIgG1 IC with high avidity and mediating important functions such as ADCC of monocytes and natural killer
(NK) cells. PoFc $\gamma$ RIIIa, in contrast, binds neither free- nor immune-complexed huIgG1, and poIgGla only with low affinity. This binding pattern was observed with recombinant soluble poFc $\gamma$ RIIIa in SPR assays with trastuzumab and with HEK293F cells and neutrophils expressing poFc $\gamma$ RIIIa in interaction with bevacizumab (Figs. 1, 2 and 4). The nature of the poor binding properties of poFc $\gamma$ RIIIa is unknown. However, we cannot exclude binding to other porcine or human IgG subclasses. Similarly, it is known that huIgG isotypes bind differently to mouse Fc $\gamma \mathrm{R}_{\mathrm{s}}$ than mouse IgG isotypes (39). The strong surface expression of FcyRIIIa on porcine monocytes, eosinophils, neutrophils and NK cells suggests important roles for effector functions involving these cell types. Possibly, poFc $\gamma$ RIIIa mediates such functions in with poIgGla IC or in association with other poIgG isotypes. Indeed, $11 \mathrm{Ig}$ heavy constant gamma (IGHG) genes coding for six different IgG subclasses exist in pigs whose specific functions are still unknown (40).

Interestingly, an influenza virus study in landrace cross pigs by Morgan, Holzer (41) reported a lack of efficacy of a hemagglutinin-specific huIgGl antibody that was expected to reduce the viral load via FcyR-interaction. The mechanistic investigation by flow cytometry revealed no significant binding of free- and immune-complexed huIgGl to porcine peripheral blood mononuclear cells including lymphocytes and monocytes, even though a slight elevation of positive cells was observed with IC. However, the results from the present study show that large IC, but not free huIgG1 below $10 \mu \mathrm{g} / \mathrm{ml}$ bind to monocytes and weakly to a lymphocyte subset (Fig. 4). These results are difficult to compare to our study due to the unknown huIgGl concentration, unreported gating, and uncharacterized IC in the publication. Importantly, Morgan, Holzer (41) have shown that the therapeutic huIgGl antibody does not elicit ADCG by porcine PBMCs and thus concluded a lacking interaction between huIgG1 and all poFc $\gamma$ Rs. The present study confirms the lacking interaction between huIgG1 and poFc $\gamma$ RIIIa, that is an important mediator of ADCG in monocytes and NK cells. Nevertheless, we found that huIgGl antibodies bind to all other poFc $\gamma$ Rs. Even though no reduction of the viral load was observed due to lacking ADCC, the said study reported reduced gross pathology (decreased surface of lung lesion) with the hemagglutinin antibody and the huIgG1 control. As proposed before, this finding could be explained by the strong binding huIgGl to poFc $\gamma$ RIIb and the expression of this receptor on porcine monocytes. The inhibitory function of poFc $\gamma$ RIIb could thus lead to a monocytemediated anti-inflammatory effect in interaction with huIgG1 complexes and therefore to reduced tissue damage. On the other hand, the inhibition could be another reason for the unaffected viral load in addition to the lack of NK cell-mediated ADCG. 


\section{CONCLUSION}

In this study, we identified similarities and differences between porcine and human $\mathrm{F} c \gamma \mathrm{Rs}$ regarding binding to huIgG. Taken together, we inferred proper Fc $\gamma$ Rmediated effector functions upon treatment of minipigs with human therapeutic antibodies. Due to the similar binding properties of Fc $\gamma$ RIa, Fc $\gamma$ RIIa, and Fc $\gamma$ RIIb we suggest the minipig as a valuable species for assessment of IC-mediated toxicities such as bevacizumab induced platelet activation. The limitations of the minipig relate to the failure of poFc $\gamma$ RIIIa to bind huIgG1 antibodies to mediate effects such as ADCG as demonstrated by the influenza study in pigs with a huIgG1 antibody discussed before (41). Because minipig NK cells express poFc $\gamma$ RIIIa as the only $\mathrm{Fc} \gamma \mathrm{R}$, we conclude that this cell type cannot mediate ADCG and other effector functions via huIgGl. However, monocyte-mediated effector functions cannot be excluded with huIgG1 because this cell type expresses other Fc $\gamma$ Rs in addition to poFc $\gamma$ RIIIa. Nevertheless, a reduced or lacking efficacy of huIgGl antibodies is expected in the minipig. Furthermore, as in most animal species for preclinical studies, also FcyRIIIb-mediated effects of neutrophils, such as acute infusion reactions, cannot be predicted in the minipig due to the unique expression of FcyRIIIb in the human (42). However, the minipig is well suited for pharmacodynamic (PD) studies with therapeutic antibodies as comparable binding strengths of huIgGs were observed to the neonatal Fc receptor $\left(\mathrm{Fc}_{\mathrm{C} n}\right)$ between minipigs and humans (43). Nevertheless, it has to be mentioned that the selection of the Göttingen minipig for preclinical studies is dependent on the pharmacological activity of the therapeutic antibody and thus cross-reactivity with the porcine target is required. Furthermore, in vitro functional studies and activity assays should be performed to assess the pharmacology of a particular therapeutic antibody prior to the selection of the minipig for preclinical studies.

Here we have described for the first time the cloning and expression of poFc $\gamma$ RIIa, as well as the binding pattern of human therapeutic antibodies to all poFc $\gamma$ Rs. The Interaction Map analysis used in this study is a tool to understand complex binding mechanisms in vitro and highlights the complexity of Fc $\gamma$ R-IgG interactions. Furthermore, it relativizes statements about Fc $\gamma \mathrm{R}$ affinities in interaction with $\operatorname{IgG}$. Additionally, many novel special formats of therapeutic antibodies are often $\mathrm{Fc}$ engineered for altered $\mathrm{F} c \gamma \mathrm{R}$ binding influencing their mode of action. The binding properties of these novel antibody formats to minipig Fc $\gamma$ Rs can thus not easily be predicted from our data and will have to be established in a case by case evaluation. The experimental systems described here provide a suitable basis of tools for such evaluation.
ACKNOWLEDGMENTS AND DISCLOSURES. The authors J.E, T.S, C.S, S.S, D.S, and A.I are employees of F. Hoffmann-La Roche, Ltd. No further funding was received from funding agencies in the public, commercial, or not-for-profit sectors. The authors acknowledge Petra Rüger, Hubert Hertenberger, Daniel Mona, and Dominique Burger for assistance in protein purification and analysis, Martin Nussbaumer for help in protein expression, and Guy Georges for molecular modeling.

Open Access This article is distributed under the terms of the Creative Commons Attribution 4.0 International License (http://creativecommons.org/licenses/by/4.0/), which permits unrestricted use, distribution, and reproduction in any medium, provided you give appropriate credit to the original author(s) and the source, provide a link to the Creative Commons license, and indicate if changes were made.

Publisher's Note Springer Nature remains neutral with regard to jurisdictional claims in published maps and institutional affiliations.

\section{REFERENCES}

1. Nimmerjahn F, Ravetch JV. Fcgamma receptors as regulators of immune responses. Nat Rev Immunol. 2008;8:34-47.

2. Akula S, Mohammadamin S, Hellman L. Fc receptors for immunoglobulins and their appearance during vertebrate evolution. PLoS One. 2014;9(5):e96903.

3. Wang X, Mathieu M, Brezski RJ. IgG Fc engineering to modulate antibody effector functions. Protein Cell. 2018;9(1):63-73.

4. Cymer F, Beck H, Rohde A, Reusch D. Therapeutic monoclonal antibody N-glycosylation - structure, function and therapeutic potential. Biologicals. 2018;52:1-11.

5. MacDonald DA, Martin J, Muthusamy KK, Luo JK, Pyles E, Rafique A, et al Aflibercept exhibits VEGF binding stoichiometry distinct from bevacizumab and does not support formation of immune-like complexes. Angiogenesis. 2016;19(3):389-406.

6. Meyer T, Robles-Carrillo L, Robson T, Langer F, Desai H, Davila $\mathrm{M}$, et al. Bevacizumab immune complexes activate platelets and induce thrombosis in FGGR2A transgenic mice. J Thromb Haemost. 2009;7(1):171-81.

7. Rubic-Schneider T, Christen B, Brees D, Kammuller M. Minipigs in translational immunosafety sciences: a perspective. Toxicol Pathol. 2016;44(3):315-24.

8. Ganderup NC, Harvey W, Mortensen JT, Harrouk W. The minipig as nonrodent species in toxicology-where are we now? Int J Toxicol. 2012;31(6):507-28.

9. van der Laan JW, Brightwell J, McAnulty P, Ratky J, Stark C, Steering Group of the RP. Regulatory acceptability of the minipig in the development of pharmaceuticals, chemicals and other products. J Pharmacol Toxicol Methods. 2010;62(3):184-95.

10. van Mierlo GJ, Cnubben NH, Wouters D, Wolbink GJ, Hart MH, Rispens $\mathrm{T}$, et al. The minipig as an alternative non-rodent model for 
immunogenicity testing using the TNFalpha blockers adalimumab and infliximab. J Immunotoxicol. 2014;1 1(1):62-71.

11. Colleton C, Brewster D, Chester A, Clarke DO, Heining P, Olaharski A, et al. The use of Minipigs for preclinical safety assessment by the pharmaceutical industry: results of an IQ DruSafe Minipig survey. Toxicol Pathol. 2016;44(3):458-66.

12. Bode G, Clausing P, Gervais F, Loegsted J, Luft J, Nogues V, et al. The utility of the minipig as an animal model in regulatory toxicology. J Pharmacol Toxicol Methods. 2010;62(3):196-220.

13. Descotes J, Allais L, Ancian P, Pedersen HD, Friry-Santini C, Iglesias A, et al. Nonclinical evaluation of immunological safety in Gottingen Minipigs: the CONFIRM initiative. Regul Toxicol Pharmacol. 2018;94:271-5.

14. Qiao S, Zhang G, Xia C, Zhang H, Zhang Y, Xi J, et al. Cloning and characterization of porcine $\mathrm{Fc}$ gamma receptor II (FcgammaRII). Vet Immunol Immunopathol. 2006;114(1-2): 178-84.

15. Zhang G, Qiao S, Li Q, Wang X, Duan Y, Wang L, et al. Molecular cloning and expression of the porcine high-affinity immunoglobulin G Fc receptor (FcgammaRI). Immunogenetics. 2006;58(10):845-9.

16. Egli J, Schmucki R, Loos B, Reichl S, Grabole N, Roller A, et al. The genomic organization and expression pattern of the lowaffinity $\mathrm{Fc}_{\mathrm{c}}$ gamma receptors $(\mathrm{F} c \gamma \mathrm{R})$ in the Göttingen minipig. Immunogenetics.2019; 71:123-136.

17. Warncke M, Calzascia T, Coulot M, Balke N, Touil R, Kolbinger $\mathrm{F}$, et al. Different adaptations of IgG effector function in human and nonhuman primates and implications for therapeutic antibody treatment. J Immunol. 2012;188(9):4405-1 1.

18. Chan YN, Boesch AW, Osei-Owusu NY, Emileh A, Crowley AR, Cocklin SL, et al. IgG binding characteristics of rhesus macaque FcgammaR. J Immunol. 2016;197(7):2936-47.

19. Dekkers G, Bentlage AEH, Stegmann TC, Howie HL, LissenbergThunnissen S, Zimring J, et al. Affinity of human IgG subclasses to mouse Fc gamma receptors. MAbs. 2017;9(5):767-73.

20. Schlothauer T, Herter S, Koller GF, Grau-Richards S, Steinhart V, Spick C, et al. Novel human IgGl and IgG4 Fc-engineered antibodies with completely abolished immune effector functions. Protein Eng Des Sel. 2016;29(10):457-66.

21. Lammers BM, Beaman KD, Kim YB. Sequence analysis of porcine immunoglobulin light chain cDNAs. Mol Immunol. 1991;28(8): 877-80.

22. Butler JE, Wertz N. Antibody repertoire development in fetal and neonatal piglets. XVII. IgG subclass transcription revisited with emphasis on new IgG3. J Immunol. 2006;177(8):5480-9.

23. Altschuh D, Bjorkelund H, Strandgard J, Choulier L, Malmqvist M, Andersson K. Deciphering complex protein interaction kinetics using interaction map. Biochem Biophys Res Commun. 2012;428(1):74-9.

24. Hayes JM, Frostell A, Cosgrave EF, Struwe WB, Potter O, Davey GP, et al. Fc gamma receptor glycosylation modulates the binding of IgG glycoforms: a requirement for stable antibody interactions. J Proteome Res. 2014;13(12):5471-85.

25. Xia P, Liu Y, Liu X, Zhang Z, Duan E, Lu X, et al. Molecular cloning and characterization of a porcine Fc gamma RIIb subisoform(FcgammaRIIb 1). Vet Immunol Immunopathol. 2011;141(1-2):144-50.

26. Daeron M. Fc receptor biology. Annu Rev Immunol. 1997;15(1): 203-34.
27. Fairbairn L, Kapetanovic R, Beraldi D, Sester DP, Tuggle CK, Archibald AL, et al. Comparative analysis of monocyte subsets in the pig. J Immunol. 2013;190(12):6389-96.

28. Bruhns P, Iannascoli B, England P, Mancardi DA, Fernandez N, Jorieux $\mathrm{S}$, et al. Specificity and affinity of human Fcgamma receptors and their polymorphic variants for human IgG subclasses. Blood. 2009;113(16):3716-25.

29. Kiyoshi M, Caaveiro JM, Kawai T, Tashiro S, Ide T, Asaoka Y, et al. Structural basis for binding of human IgG1 to its high-affinity human receptor FcgammaRI. Nat Commun. 2015;6:6866.

30. Chenoweth AM, Trist HM, Tan PS, Wines BD, Hogarth PM. The high-affinity receptor for IgG, FcgammaRI, of humans and nonhuman primates. Immunol Rev. 2015;268(1):175-91.

31. Lux A, Nimmerjahn F. Of mice and men: the need for humanized mouse models to study human IgG activity in vivo. J Clin Immunol. 2013;33(Suppl 1):S4-8.

32. Trist HM, Tan PS, Wines BD, Ramsland PA, Orlowski E, Stubbs J, et al. Polymorphisms and interspecies differences of the activating and inhibitory FcgammaRII of Macaca nemestrina influence the binding of human IgG subclasses. J Immunol. 2014;192(2):792803.

33. Qureshi OS, Rowley TF, Junker F, Peters SJ, Crilly S, Compson J, et al. Multivalent Fcgamma-receptor engagement by a hexameric Fc-fusion protein triggers Fcgamma-receptor internalisation and modulation of Fcgamma-receptor functions. Sci Rep. 2017;7(1): 17049 .

34. Lau C, Gunnarsen KS, Hoydahl LS, Andersen JT, Berntzen G, Pharo A, et al. Chimeric anti-CD14 IGG2/4 hybrid antibodies for therapeutic intervention in pig and human models of inflammation. J Immunol. 2013;191(9):4769-77.

35. Guilliams M, Bruhns P, Saeys Y, Hammad H, Lambrecht BN. The function of Fcgamma receptors in dendritic cells and macrophages. Nat Rev Immunol. 2014;14(2):94-108.

36. Clatworthy MR, Smith KG. FcgammaRIIb balances efficient pathogen clearance and the cytokine-mediated consequences of sepsis. J Exp Med. 2004;199(5):717-23.

37. Brownlie RJ, Lawlor KE, Niederer HA, Cutler AJ, Xiang Z, Clatworthy MR, et al. Distinct cell-specific control of autoimmunity and infection by FcgammaRIlb. J Exp Med. 2008;205(4):883-95.

38. Li F, Smith P, Ravetch JV. Inhibitory Fcgamma receptor is required for the maintenance of tolerance through distinct mechanisms. J Immunol. 2014;192(7):3021-8.

39. Jonsson F, Mancardi DA, Albanesi M, Bruhns P. Neutrophils in local and systemic antibody-dependent inflammatory and anaphylactic reactions. J Leukoc Biol. 2013;94(4):643-56.

40. Butler JE, Wertz N, Deschacht N, Kacskovics I. Porcine IgG: structure, genetics, and evolution. Immunogenetics. 2009;61(3):209-30.

41. Morgan SB, Holzer B, Hemmink JD, Salguero FJ, Schwartz JC, Agatic G, et al. Therapeutic administration of broadly neutralizing FI6 antibody reveals lack of interaction between human IgG1 and pig Fc receptors. Front Immunol. 2018;9:865.

42. Weber F, Breustedt D, Schlicht S, Meyer CA, Niewoehner J, Ebeling $\mathrm{M}$, et al. First infusion reactions are mediated by FcgammaRIIIb and neutrophils. Pharm Res. 2018;35(9):169.

43. Zheng Y, Tesar DB, Benincosa L, Birnbock H, Boswell CA, Bumbaca D, et al. Minipig as a potential translatable model for monoclonal antibody pharmacokinetics after intravenous and subcutaneous administration. MAbs. 2012;4(2):243-55. 